\title{
Controlled Synthesis and Surface Functionalization of ZnO Quantum Dots
}

\author{
Luis M. Montes-de-Oca ${ }^{1}$, Ana Hernandez-Prudencioº ${ }^{2}$, Salomón E. Borjas-García ${ }^{1}$, Gabriel \\ Espinosa $^{1}$, Nikte M Gomez-Ortiz ${ }^{1}$ and P. Martínez-Torres ${ }^{1}$ \\ 1. Instituto de Física y Matemáticas, Universidad Michoacana de San Nicolás de Hidalgo, \\ Morelia, Michoacán, México \\ 2. Facultad de Ingeniería Químicas, Universidad Michoacana de San Nicolás de Hidalgo, Morelia, \\ Michoacán, México
}

Zinc Oxide $(\mathrm{ZnO})$ is a non-toxic metal oxide semiconductor with a wide band gap of $\sim 3.37 \mathrm{eV}$ at room temperature and a large exciton binding energy of $60 \mathrm{meV}$ [1]. $\mathrm{ZnO}$ as quantum dots (Qdots) has been used in cell imaging [2] and in selective detection of aldehydes [3]. ZnO nanostructures can be synthesized by several methods, such as sol-gel, hydrothermal synthesis, controlled precipitation, using microemulsion environment and by metallurgical process [4]. Sol-gel method is particularly interesting due to their simplicity, low cost and repeatability [4], even though, the synthesis in a controlled and repeatable way is still challenging. In this work, we conducted the synthesis of ZnO Qdots in a controlled way, using a recirculating bath and syringe pumps during the reaction stage. We also conducted the surface functionalization of the $\mathrm{ZnO}$ Qdots to render their surface partially hydrophobic using trimetoxy(octadecyl)silane (ODS) and obtaining ZnO@ODS nanoparticles.

$\mathrm{ZnO}$ Qdots were prepared by a sol-gel process from $\mathrm{Zn}$ acetate (Sigma) and $\mathrm{NaOH}$ (Sigma) as precursors. For a typical synthesis, $0.002 \mathrm{~mol}$ of $\mathrm{Zn}$ acetate were dissolved in $30 \mathrm{ml}$ of ethanol at $70^{\circ} \mathrm{C}$ and $0.005 \mathrm{~mol}$ of $\mathrm{NaOH}$ dissolved in $30 \mathrm{ml}$ of ethanol at $50-60^{\circ} \mathrm{C}$ so that, we had a $\left[\mathrm{OH}^{-}\right] /\left[\mathrm{Zn}^{2+}\right]$ ratio of 2.5. The $\mathrm{Zn}^{2+}$ solution was cooled and controlled at $0^{\circ} \mathrm{C}$ using a bath circulator (HAAKE A10, Thermo scientific) and the $\mathrm{OH}^{-}$solution was added into the $\mathrm{Zn}^{2+}$ solution dropwise. We filled two syringes (20 $\mathrm{mL}$, Beckton-Dickinson) with the $\mathrm{OH}^{-}$solution and controlled the time of dripping using syringe pumps (Kent Scientific) with programmed flow ratios. ZnO Qdots were synthesized at different times of $1 / 2 \mathrm{~h}, 1$ $\mathrm{h}$ and $1 \frac{1}{2} \mathrm{~h}$. The resulting $\mathrm{ZnO}$ nanoparticles were precipitated by the addition of $\mathrm{n}$-heptane to the solution containing the nanoparticles at a volume ratio of $3: 2$. The resulting precipitate was rinsed three times with ethanol and centrifuged at $3000 \mathrm{rpm}$ during 10 minutes. The resulting $\mathrm{ZnO}$ Qdots were dried in an oven at $40^{\circ} \mathrm{C}$ during one day and stored.

The ZnO@ODS nanoparticles were obtained by coating the ZnO Qdots with the hydrophobic ODS layer by the hydrolytic silanization procedure in ethanol. It was prepared four solutions at 2\%, 4\%, 6\% and $8 \% \mathrm{v} / \mathrm{v}$ of ODS in $1 \mathrm{mg} / \mathrm{mL}$ suspension of Qdots in ethanol. The mixture was stirred $1 \mathrm{~h}$ at room temperature. The resultant $\mathrm{ZnO} @ O$ ODS nanoparticles were centrifuged and rinsed three times with ethanol.

Synthesized ZnO Qdots and ZnO@ODS nanoparticles were characterized using X-ray diffraction (XRD), scanning electron microscopy and fluoresce spectroscopy. Figure 1a shows the XRD spectrum of $\mathrm{ZnO}$ Qdot sample that correspond to zincite according to the Joint Committee on Powder Diffraction Standards (JCPDS) No. 00-036-1451. Scherrer equation was used to calculate the crystal size of the $\mathrm{ZnO}$ Qdots at different times of synthesis at $0^{\circ} \mathrm{C}$ (Figure 1b). The greater the synthesis time (and the slower the drop flow), the larger diameter of the Qdots were obtained, due to larger time of synthesis the particles have more time to increase their size. 
Figure 2 shows the SEM image of the synthesized material for $1 \frac{1}{2} \mathrm{~h}$ of synthesis at $0^{\circ} \mathrm{C}$. It is observed the presence of nanoparticles with $25 \mathrm{~nm}$ in diameter with morphology of spheres. The ZnO powder was suspended in ethanol and $\mathrm{ZnO} @ O$ ODS suspended in hexane to study their photoluminescence (PL) (Figure 3). Their maximum emission intensity was at $567 \mathrm{~nm}$ for $\mathrm{ZnO}$ and $556 \mathrm{~nm}$ for $\mathrm{ZnO@ODS8 \%}$ after solvent subtraction. Finally, we observed a better dispersion of the surface modified nanoparticles in organic solvents due to their hydrophobicity [5].

References:

[1] Ü. Özgür et al. J. Appl. Phys. 41301 (2016), p. 1.

[2] S. Li et al. Sci. Rep. 5 (2015), p. 8475.

[3] N.R. Jana et al. Chem. Commun. (Camb). (2007), p. 1406.

[4] A. Kołodziejczak-Radzimska, T. Jesionowski, Materials (Basel). 7 (2014), p. 2833.

[5] This work was partially funded by Consejo de la Investigacion Cientifica UMSNH, research project 2018 and Fortalecimiento de Cuerpos Académicos Convocatoria 2017.

a)

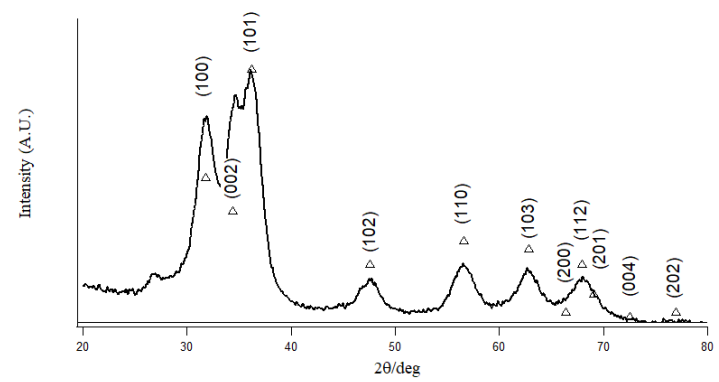

b)

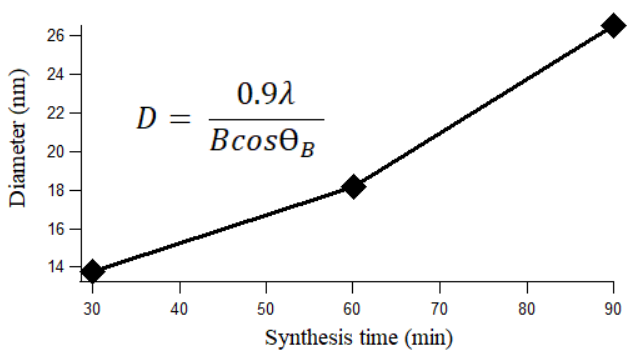

Figure 1. (a)XRD spectrum of $\mathrm{ZnO}$ Qdots from the hexagonal phase of $\mathrm{ZnO}$. (b) Average diameter of $\mathrm{ZnO}$ Qdots calculated using the Scherrer formula.

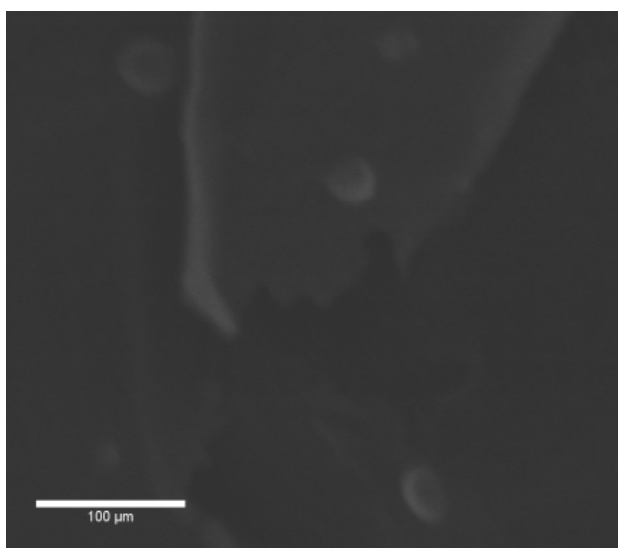

Figure 2. Scanning electron micrograph of the synthtesized $\mathrm{ZnO}$ Qdots.

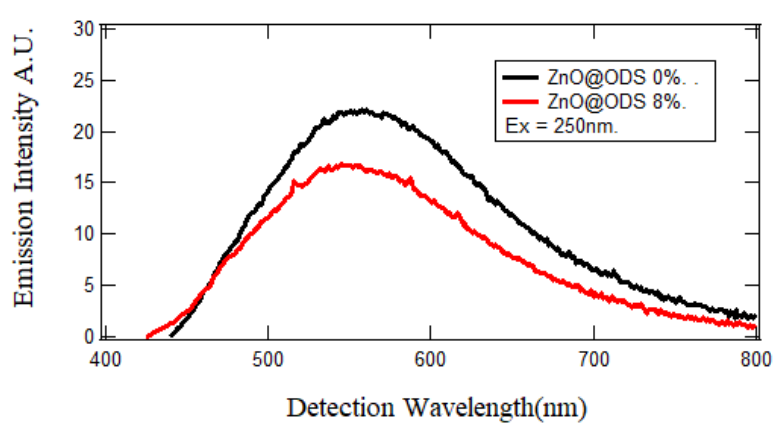

Figure 3. PL Emission spectra of the $\mathrm{ZnO}$ and $\mathrm{ZnO}$ OODS8\% nanoparticles under $250 \mathrm{~nm}$ wavelength of excitation light. 